EGU21-4960

https://doi.org/10.5194/egusphere-egu21-4960

EGU General Assembly 2021

(c) Author(s) 2021. This work is distributed under

the Creative Commons Attribution 4.0 License.

\title{
Imaging the extent of saltwater intrusion in the Luy river coastal aquifer (Binh Thuan) using electrical resistivity tomography (ERT)
}

\author{
Cong-Thi Diep \\ Ghent University, Gent, Belgium (diep.congthi@ugent.be)
}

Imaging the extent of salt water intrusion in the Luy river coastal aquifer (Binh Thuan) using electrical resistivity tomography (ERT)

Diep Cong-Thi ${ }^{1,3}$, Linh Pham Dieu ${ }^{1,3}$, Robin Thibaut ${ }^{1}$, Marieke Paepen ${ }^{1}$, Hieu Huu Ho ${ }^{3}$,

Frédéric Nguyen ${ }^{2}$, Thomas Hermans ${ }^{1}$

${ }^{1}$ Department of Geology,Ghent University, 9000-Gent, Belgium

${ }^{2}$ Department of Urban and Environmental Engineering,Liege University and Department of Civil Engineering, KU Leuven, B- 4000 Liège and 3000 Leuven, Belgium

${ }^{3}$ Department of Marine Geology, Vietnam Institute of Geosciences and Mineral Resources (VIGMR), 100000 Hanoi, Vietnam

\section{ABSTRACT}

Seawater intrusion has been one of the most concerning issues of the Vietnam South Central provinces in recent years, especially in the Binh Thuan province which is characterized by a hyperarid climate. During the dry season extending from November to April, seawater intrudes through estuaries and threatens groundwater resources. The latter are under increasing pressure due to water extraction for agri- and aquaculture. To evaluate the current state of salinity in the shallow coastal aquifer, 21 electrical resistivity tomography (ERT) measurements were collected along the downstream part of the Luy river based on the previous saltwater intrusion boundary which was estimated from water samples collected from shallow boreholes. The data were inverted to get the resistivity distribution of the subsurface and interpreted in terms of salinity. Comparison with well data shows that resistivity values below $6.5 \mathrm{Ohm}$.m correspond to the presence of saltwater in the aquifers. On the right bank of the river, a higher elevation dune area contains a freshwater aquifer which limits the intrusion of saltwater. On the left bank dominated by lowland areas, saline water fills almost the entire thickness of the aquifer, except locally for small thin freshwater lenses. At larger distances from the sea, the aquifer displays a complex distribution of fresh and saline lenses. Those variations seem to be correlated with the presence of clay lenses, recharge sources 
and irrigation practices. ERT data also reveals the depth of the rock basement. The geophysical observations show that the extension of saltwater intrusion is much larger and more complex than expected from existing borehole data and is not limited to interaction with the river.

KEYWORDS: saltwater intrusion, groundwater, electrical resistivity tomography, Luy river.

*Corresponding Authors. Email: Diep.CongThi@UGent.be; Linh.PhamDieu@Ugent.be; robin.thibaut@ugent.be;_marieke.paepen@ugent.be; hohuuhieu@yahoo.com;

f.nguyen@uliege.be; thomas.hermans@ugent.be 